\title{
Introducing a Case of Aarskog-Scott Syndrome
}

\section{ARTICLE INFO}

\section{Article Type}

Case Report

\section{Authors}

Bita Bozorgmehr ${ }^{1}$, MD*

Mohammad Reza Nateghi ${ }^{1}$, MD

Dorin Tajbakhsh², MD

1 Sarem Fertility and Infertility Research Center (SAFIR), Sarem Women's Hospital, Iran University of Medical Sciences (IUMS), Tehran, Iran

2 York University, Toronto, Canada

*Corresponding Author Address: Sarem Women Hospital, Basij Square, Phase 3, EkbatanTown, Tehran, Iran. Postal code: 1396956111 Phone: +98 (21) 44670888 Fax: +98 (21) 44670432 dr.Bozorgmehr@sarem.org

\section{ABSTRACT}

Introduction: Aarskog-Scott syndrome is a rare X-linked disorder, charecterized by facial, skeletal and genital anomalies. It is also known as faciogenital dysplasia (FGDY, OMIM NO:305400) and facio-digito-genital syndrome.

Patient Information: 7 years old boy with the same features, whom had been referred for genetic counseling, diagnosis, knowing the recurrence risk and seeking advice.

Conclusion: The main features are short stature, hypertelorism, short hands and feet, and shawl scrotum.

Keywords: Aarskog-Scott Syndrome, cognitive disorders, X- linked disorders

\section{Article History}

Received: June 01, 2019

Accepted: October 21, 2019

e Published: December 19, 2020

Copyright(C) 2020, ASP Ins. This open-access article is published under the terms of the Creative Commons Attribution-Noncommercial 4.0 International License which permits Share (copy and edistribute the material in any medium or format) and Adapt (remix, transform, and build 
(هييرتلوريسم)"، كف دست و پِاى كوتاه و يهلن و كيسه بيضه شالى شكل v

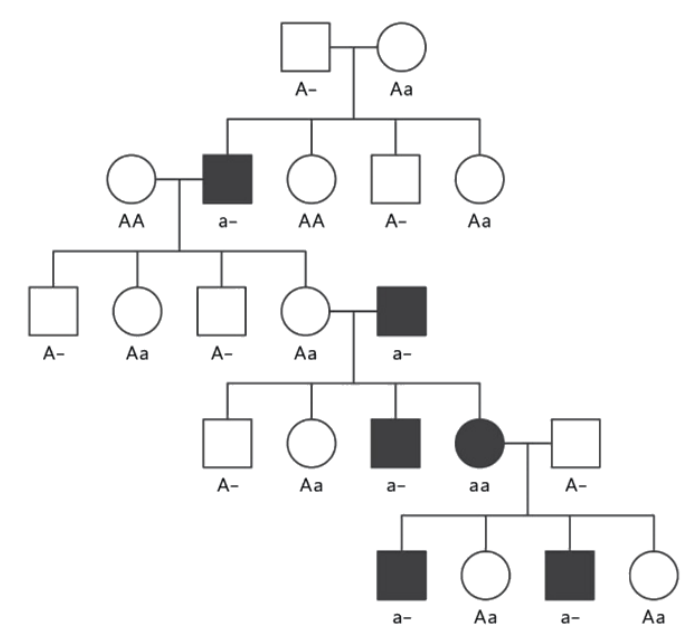

تصوير شماره ا. شجرهنامه توارث وابسته به جنس مغلوب

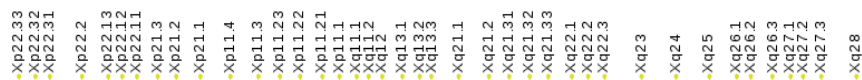

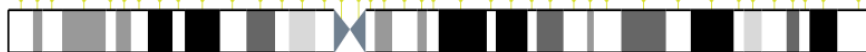

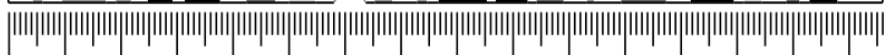

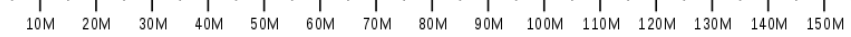

تصوير شماره r. كروموزوم X و محل قراركيرى زن FGD1:

\section{معرفى بيمار}

بيمار يك يسر بجه هفت ساله كه جهت بررسى دليل اختلال يادگيرى

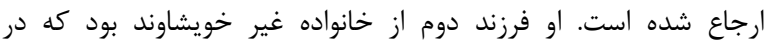

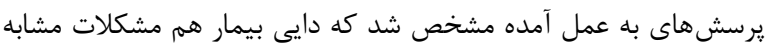

وى ماحصل زايمان طبيعى در هفته جهلم باردارى بود. در بدو تولد، وزن

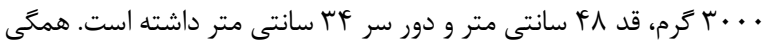

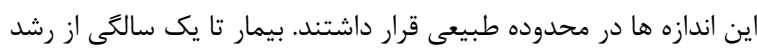

Faciogenital Dysplasia 1 Gene $^{\circ}$ Eye Hypertelorism ${ }^{\top}$ Shawl Scrotum ${ }^{\vee}$

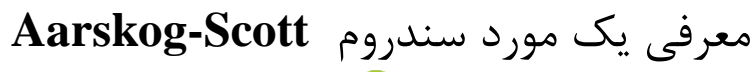

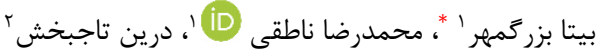
'مركز تحقيقات بارورى و نابارورى صارم، بيمارستان فوق تخصصى صارم،

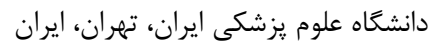

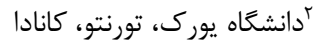

جكيده

مقدمه: سندروم ارسكاگ- اسكات يا ديسيلازى صورتى - تناسلى به

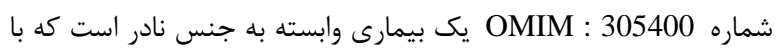

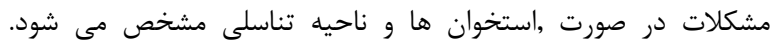

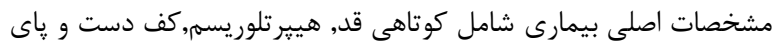
كوتاه و يهن و اسكروتوم شالى است.

بيمار و روشها: در اين گزارش پِر هفت ساله اي با اين علائم كه براى مشاوره زنتيك , تشخيص بيمارى, دانستن ريسك تكرار و كرفتن مشورت مراجعه كرده بودند , معرفى مى شود.

كليدوازهها: سندروم ارسكاگ- اسكات, عقب افتادگى ذهنى, بيمارى وابسته به جنس

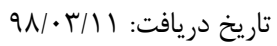

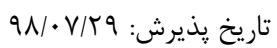

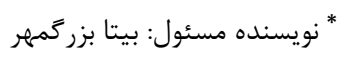

مقدمه

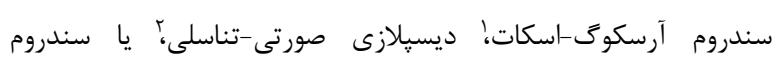

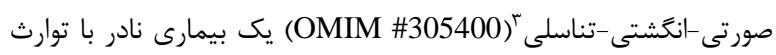

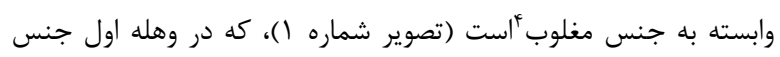

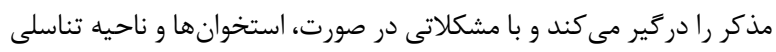

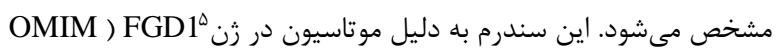

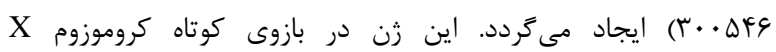

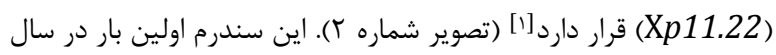
19V.

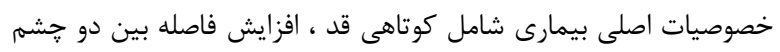

Aarskog-Scott Syndrome (AAS) Faciogenital Dysplasia (FGDY) ${ }^{r}$

Facial-Digital-Genital Syndrome ${ }^{r}$ X-linked Recessive (XLR)

دانشنامه صارم در طب بارورى

دوره أ، شماره fا، زمستان لهوبا 


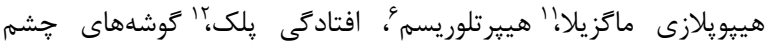

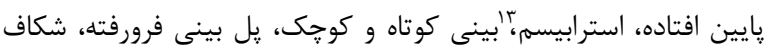

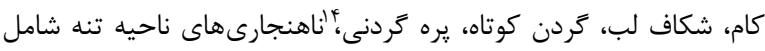

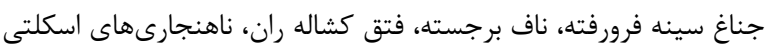

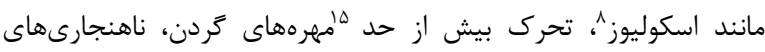

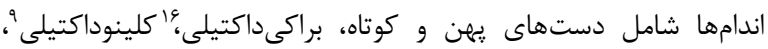

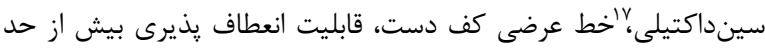

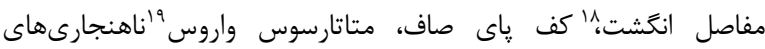

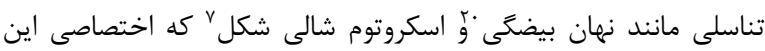

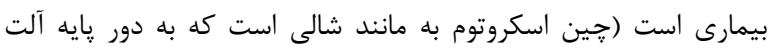

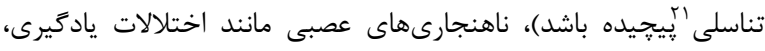

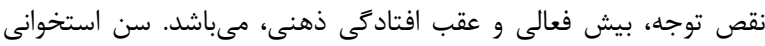

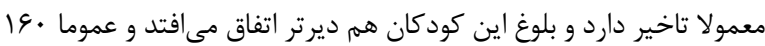

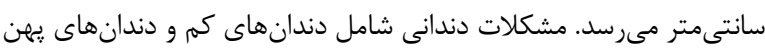

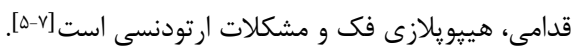

\section{نتيجه كيرى}

سندروم آرسكوگ-اسكات، يك بيمارى نادر با توارث وابسته به جنس است،

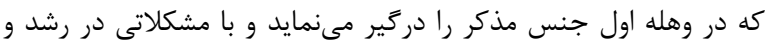

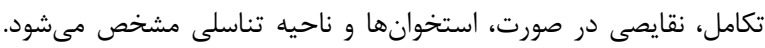

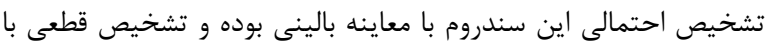

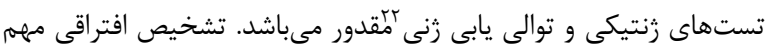

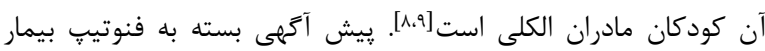

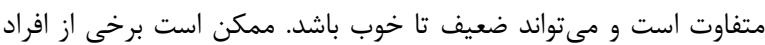

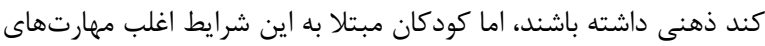

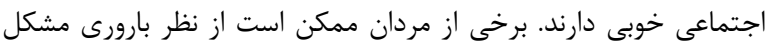

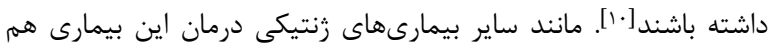

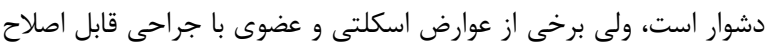

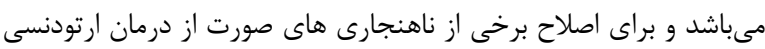

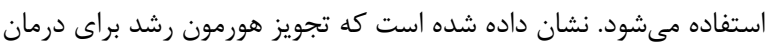

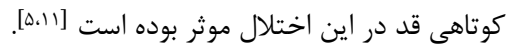

Brachydactyly Syndactyly Joint Hypermobility \^ Metatarsus Varus ${ }^{19}$ Cryptorchidism ${ }^{r}$. Penis ${ }^{r}$

Gene Sequencing ${ }^{r r}$
خوبى برخوردار بوده اما پِ از آن كاهش رشد داشته و در زمان مراجعه

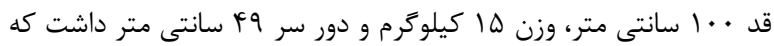

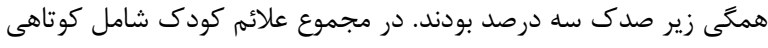

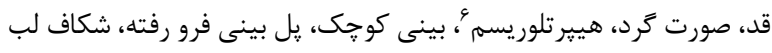

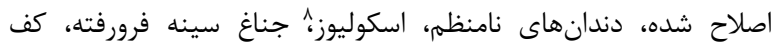
دستهاى كوتاه و يهن، كلينوداكتيلى؛ خط عرضى كف دن دست، و و در ناحيه

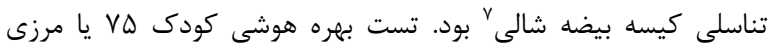
كزارش شده بود. مغز وى، تستهاى بيوشيميايى و متابوليك، اكوكارديوكرافى و

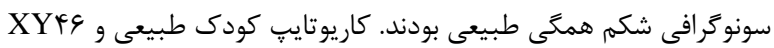
كزارش شده بود (تصوير شماره ؟َ).

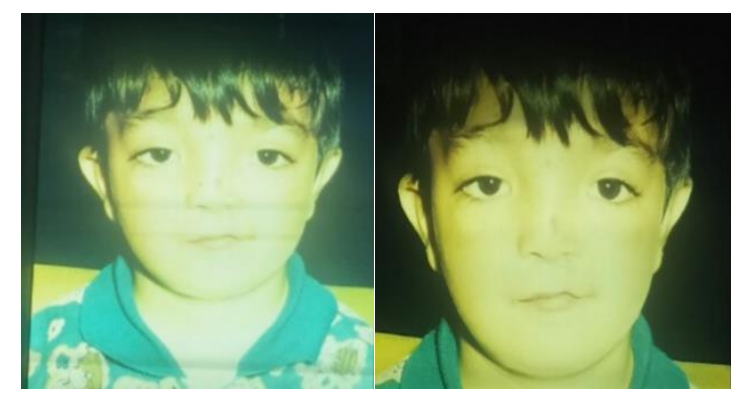

تصوير شماره ب. كودى پسر هفت ساله مبتلا به سندرم آرسكوگ-اسكات

\section{بحث}

سندروم آرسكوگ-اسكات يا ديسيلازى صورتى- تناسلى، اولين بار در سال 19V.

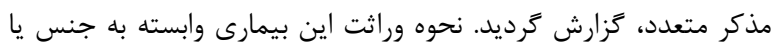

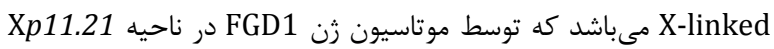

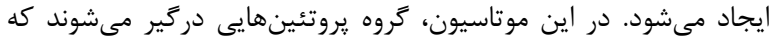

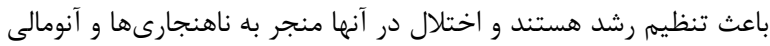

هاى رشد مى شود [ث]. علائم بالينى اين بيمارى شامل كوتاهى قد، ناهنجارىهاى سر و و صورت

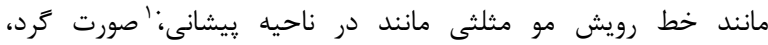


Diagnosis National Center on Birth Defects and Developmental Disabilities Centers for Disease Control and Prevention Department of Health and Human Services in coordination with DEPARTMENT OF HEALTH AND HUMAN SERVICES Centers for Disease Control and Prevention. 2004.

10- Burkardt DD, Graham Jr JM. Abnormal Body Size and Proportion. In: Emery and Rimoin's Principles and Practice of Medical Genetics and Genomics. Elsevier; 2019. p. 81-143.

11- Darendeliler F, Larsson P, Neyzi O, Price AD, Hagenäs L, Sipilä I, et al. Growth hormone treatment of Aarskog syndrome: Analysis of the KIGS (Pharmacia International Growth Database) data. J Pediatr Endocrinol Metab [Internet]. 2003 Oct 1 [cited 2020 Dec 16];16(8):1137-42. Available from: https://www.degruyter.com/view/journals/jp em/16/8/article-p1137.xml

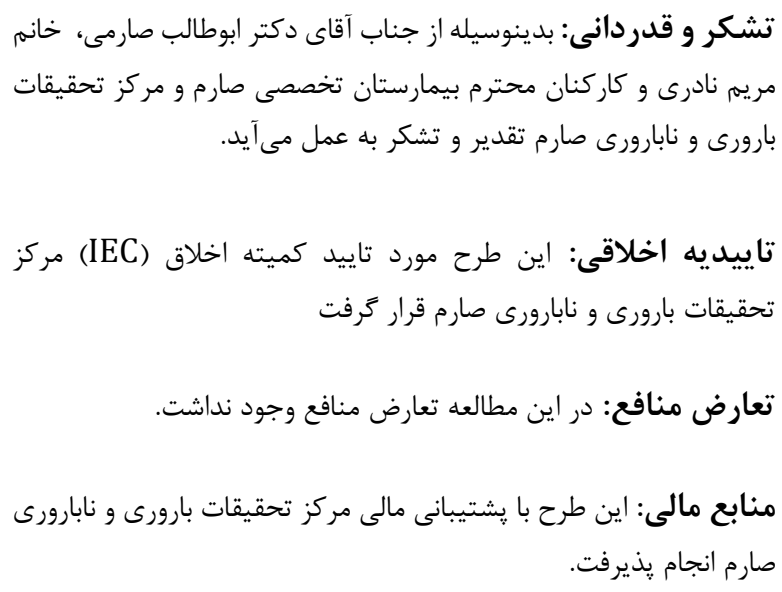

1- German Pasteris N, Cadle A, Logie LJ, Porteous MEM, Schwartz CE, Stevenson RE, et al. Isolation and characterization of the faciogenital dysplasia (Aarskog-Scott syndrome) gene: A putative RhoRac guanine nucleotide exchange factor. Cell [Internet]. 1994 Nov 18 [cited 2020 Dec 16];79(4):669-78. Available from: http://www.cell.com/article/0092867494905 525/fulltext

2- Aarskog D. A familial syndrome of short stature associated with facial dysplasia and genital anomalies. J Pediatr [Internet]. 1970 Nov [cited 2020 Dec 15];77(5):856-61. Available from: https://pubmed.ncbi.nlm.nih.gov/5504078/

3- Scott CI. Unusual facies, joint hypermobility, genital anomaly and short stature: a new dysmorphic syndrome. Birth Defects Orig Artic Ser [Internet]. 1971;7(6):240-6. Available from: https://pubmed.ncbi.nlm.nih.gov/5173168/

4- Schwartz C, Gillessen-Kaesbach G, May M, Cappa M, Gorski J, Steindl K, et al. Two novel mutations confirm FGD1 is responsible for the Aarskog syndrome. Eur J Hum Genet [Internet]. 2000 Nov [cited 2020 Dec 15];8(11):869-74. Available from: www.nature.com/ejhg

5- Closs LQ, Tovo M, Dias C, Corradi DP, Vargas IA. Aarskog-Scott Syndrome: A Review and Case Report. Int J Clin Pediatr Dent [Internet]. 2012 Dec [cited 2020 Dec 16];5(3):209-12. Available from: https://www.ijcpd.com/doi/10.5005/jpjournals-10005-1168

6- Goodman RM, Gorlin RJ. The malformed infant and child: an illustrated guide. Oxford University Press; 1983.

7- Smith DW, Jones KL. Smith's recognizable patterns of human malformation. 6th ed. WB Saunders Company; 2006.

8- Berry C, Cree J, Mann T. Aarskog's syndrome. Arch Dis Child [Internet]. 1980 [cited 2020 Dec 16];55(9):706-10. Available from: /pmc/articles/PMC1627010/?report=abstract

9- Gerberding JL, Cordero J. Fetal Alcohol Syndrome: Guidelines for Referral and 